\title{
The Determinants of Economic Growth in Iran Based on Bayesian Model Averaging
}

\author{
Mohsen Mehrara*, Sadeq Rezaei \\ Faculty of Economics, University of Tehran, Tehran, Iran \\ *E-mail address: mmehrara@ut.ac.ir, sadeqrezaie@ut.ac.ir
}

\begin{abstract}
This paper identifies the key determinants of economic growth in Iran, using annual time series data from 1974 to 2010. There is a very large literature on determinants of economic growth and several studies have included a large number of explanatory variables. Empirical models of economic growth are therefore plagued by problems of model uncertainty concerning the choice of explanatory variables and model specification. We utilize Bayesian Model Averaging (BMA) to resolve these model uncertainties. The results of this study indicate that the ratio of oil revenue to GDP is the most important variable affecting economic growth in the Iranian economy. Also the second and third effective variables on growth are respectively the ratio of imported capital and intermediate goods to GDP and labor force which lead to an increase in growth. Endogenous growth factors which are the factors contributing to the formation of human capital, not possess a large role in growth process. Therefore, the nature of Iran's economy has not endogenous and dynamic features and predominantly, economic growth has been made by injecting of exogenous sources (oil revenue, imported capital and intermediate goods, and labor force).
\end{abstract}

JEL classifications: C11, H51, O10, 040.

Keywords: Economic growth; Bayesian Model Averaging (BMA); Iranian economy

\section{INTRODUCTION}

Over the last two decades, hundreds of empirical studies have attempted to identify the determinants of growth. There is a very large literature on determinants of economic growth and several studies have included a large number of explanatory variables in so-called "kitchen sink" regressions. A problem is that theories of economic growth are often not mutually exclusive and the validity of one theory does not necessarily imply that another theory is false. This is not to say that growth theories are of no use for that purpose. Rather, the problem is that different growth theories are typically compatible with one another. For example, a theoretical view holding that trade openness matters for economic growth is not logically inconsistent with another theoretical view that emphasizes the role of human capital in growth. Sometimes growth theory can support choices of specific variables, but the inclusion or exclusion of most variables is typically arbitrary, a phenomenon labeled the "open-endedness" of growth theory (Brock and Durlauf, 2001). In addition, while theory may provide general qualitative variables (such as human capital), it does not tell us how these variables are to be specified or measured. We are thus faced with (at least) two types of uncertainty, each of which brings about model uncertainty. Since there exist a wide set of 
possible model specifications, we often obtain contradictory conclusions. To make matters worse, estimation results are often not robust to small changes in model specification, making credible interpretations of the results hazardous. A proper treatment of model uncertainty is clearly important. One such treatment is model averaging, where the aim of the investigator is not to find the best possible model, but rather to find the best possible estimates. Each model contributes information about the parameters of interest, and all these pieces of information are combined taking into account the trust we have in each model, based on our prior beliefs and on the data (Magnus et al, 2010).In order to combine model selection and estimation, the Bayesian method offers a natural framework.

This paper sets out a BMA approach to assess how macroeconomic factors affect the economic growth in Iran during 1974-2010. Section 2 and section 3 presents a brief review of theoretical and empirical literature on growth respectively. We also present the empirical results of the paper in section 4 , and section 5 concludes.

\section{THEORETICAL LITERATURE}

In the neoclassical growth model (Solow, 1956), growth around a steady state is determined by rates of physical capital accumulation, population growth, and exogenous technological progress. The initial income of an economy is relevant for its transition path as countries with a lower initial income are expected to grow faster than richer countries. The "new growth" theories seek to explain also the previously exogenous components of economic growth, which is why they are often called "endogenous" growth models. A frequently used empirical model for growth regressions is the human capital-augmented neoclassical model (Mankiw et al., 1992), which regresses the average growth rate of GDP per capita on investment, the log of initial GDP per capita, the population growth rate, and a human capital variable. Since the seminal studies of Kormendi and Meguire (1985) and Barro (1991), empirical research on the determinants of economic growth has identified numerous variables as being robustly (partially) correlated with productivity growth in an economy. Durlauf et al. (2005) list 145 potential right-hand side variables for growth regressions and cluster them into more than forty areas (or theories), such as human capital, finance, government, and trade. We try to consider several variable cases on this study and investigate effect of them to Iranian economic growth.

\section{EMPIRICAL STUDIES}

The basic equations of BMA were first presented by Leamer (1978, Sections 4.4_4.6), who proposed Bayesian averaging of Bayesian estimates. In the context of growth econometrics, BMA was first applied by Fernández et al. (2001a) and Brock and Durlauf (2001). BMA is flexible with respect to the size and exact specification of a model and it does not require the a priori selection of any model. Inference is based on a weighted average over all models. In growth econometrics, BMA has proved useful, and recent applications include León-González and Montolio (2004), Sala-i-Martin et al. (2004) and Masanjala and Papageorgiou (2007). Recently, interest is growing in different aspects of growth empirics, such as nonlinearities, parameter heterogeneity, and endogeneity. BMA is also applied in other areas of economics; see for example Tsangarides et al. (2004), Crespo-Cuaresma and 
Doppelhofer (2007), Eicher et al. (2007a,c), Masanjala and Papageorgiou (2008) and Prüfer and Tondl (2008). In short, BMA has become an important technique (Magnus et al, 2010).

Many studies have been conducted on issue of determinants of economic growth, which generally can be divided into two categories; cross - country and time series studies that have been investigated for one economy or country.

In studies which had been used data of several country, because of exist of sufficient number of data, the number of regressors is large, so these studies is good guidance to observe interaction of variables. Fischer (1993), Gregorio(1993), Barro and Sala- i- Martin (1995), Gani(1998), Cuaresma et al(2009), Moral-Benito (2010), Magnus, Owen \& Patricia (2010), was some of these studies.

Second cases include time series studies that was investigated economic growth in one country. Such Sánchez (1998) on Spanish economy, Wang Yan \& YAO Yudong (2002) on China economy, Phimphan thavong (2014) on Laos economy, Amanzadeh (1995), Asali \& et al (1998), Dargahi \& ghadiri (2003) and Dejpasand (2005) on Iranian economy. In the experimental results can be seen economic growth is the result of many factors, some of them have been stated in growth theories, and some economic variables experimentally have been added to simple models. Selected variables are motivated by their importance for theory or policy. But as researchers disagree on what is most important, there is usually only partial overlap among the variables considered in different empirical papers. Many factors inhibiting and facilitating economic growth have been suggested. Therefore it is necessary to try and to see which of the explanatory variables suggested in the literature emerge as growth determinants.

\section{DATA AND EMPIRICAL RESULTS}

In both theoretical and empirical studies, many different kinds of variables have been considered as significant determinants of economic growth. So in this research, by application of the method of Bayesian Model Averaging (BMA), the effects of influential factors on economic growth which have been regarded in previous studies are investigated. We use Stata program to obtain the coefficient of BMA estimates.

\subsection{Data}

The variables used in the model are from time series data between1974-2010. All of the data is obtained from Central Bank of Iran (CBI). The variables are regarded based on growth rate and ratio, though all the variables are stationary. Each of variables of model has been presented briefly in Table (1). In advance we concisely explain about some variables of this model.

oThe dependent variable is growth of GDP. Therefore we investigate influential variables on it. The growth of GDP is the most frequently used proxy of economic growth.

oAccording to neoclassical growth theory, labor and capital is a major factor in economic growth. Natural resources (such as oil, minerals, etc.) are also a factor in economic growth models besides these factors. In our country, the aforementioned is factors of economic growth. The proportion of the working population to total population, indicator of labor force, the ratio of Oil revenue to nominal GDP, proxy of natural resources has been considered. 
o Other factors that contribute to economic growth, is investment. The importance of investing for the economic development of communities on most theories of economic growth and development has been emphasized. The ratio of government real investment to GDP, and the ratio of private real investment to GDP have been used as proxy of physical investment.

oAmong other factors, healthcare expenditures and human capital variables which have widely been researched and proved to a considerable impact on the economic growth of countries. Already researchers use educational attainment as a proxy for human capital stock (Barro \& Lee, 2000). Earlier empirical studies have used school enrollment ratios or literacy rates to capture educational attainment. Mankiw, Romer, and Weil (1992) used the proportion of adult population enrolled in secondary school as a proxy for human capital investment. For considering these factors, the ratio of hygiene and treatment expenditure to GDP, the ratio of education department expenditure to GDP, and ratio of the number of public high school student to population are used.

oThe relationship between trade openness and growth is a highly debated topic in the growth and development literature. Yet, this issue is far from being resolved. Theoretical growth studies suggest at best a very complex and ambiguous relationship between trade restrictions and growth. The endogenous growth literature has been diverse enough to provide a different array of models in which trade restrictions can decrease or increase the worldwide rate of growth (see Romer, 1990; Grossman and Helpman, 1990; Rivera-Batiz and Romer, 1991a,b; Matsuyama, 1992). Like other studies, we were used ratio of exports plus imports to GDP as proxy of trade openness.

oFinancial development is considered by many economists to be of paramount importance for output growth (Christopoulos et al 2004). A problem with the previous studies is that a positive relationship between financial development and output growth can exist for different reasons. As output increases the demand for financial service increases too, which in turn has a positive effect on financial development. Other things being equal, it is financial development that follows output growth and not the opposite. This issue was considered in Robinson (1952, p. 86). Others were keener to totally dismiss the impact of financial development on economic growth. Lucas (1988, p. 6) states, for example, that "the importance of financial matters is very badly overstressed" while Chandavarkar (1992, p. 134) notes "none of the pioneers of development economics . . even list finance as a factor of development'. See also Luintel and Khan (1999). Although many empirical studies have investigated the relationship between financial development, defined as the level of development of financial markets, and economic growth, the results are ambiguous. The ratio of total private sector loans of banks and credit institutes to nominal GDP, and lag of ratio of $\mathrm{M}_{2}$ (broad money) to GDP has been used as financial development indices.

oThe academic literature contains a lot of theoretical work on the costs of inflation, as reviewed recently by Briault (1995). This analysis provides a presumption that inflation is a bad idea, but the case is not decisive without supporting empirical findings. Although some empirical results (also surveyed by Briault) suggest that inflation is harmful, the evidence is not overwhelming. It is therefore important to carry out additional empirical research on the relation between inflation and economic performance (Barro 2013). The inflation rate between1974 to 2010 has been used to survey this relationship.

oSince large portion of inputs (such as raw materials, intermediate and capital) which used on supply sector in Iran are imported. Therefore, a variation of exchange rate is important for producers. Each increase in the exchange rate will increase the productions 
costs. Consequently, will limit economic growth. Growth of exchange rate of U.S dollar's (in unofficial market) on this period has been used.

oBlack market or underground economy is significant obstacle for developing countries. Based on some of economic growth studies in Iran and World, we used logarithm of the ratio of unofficial exchange rate to official exchange rate as proxy of black market or underground economy.

○ Inequality can influence growth positively by providing incentives for innovation and entrepreneurship (Lazear and Rosen, 1981); by raising saving and investment if rich people save a higher fraction of their income (Kaldor, 1957); and, perhaps especially relevant for poor countries, by allowing at least a few individuals to accumulate the minimum needed to start businesses and get a good education (Barro, 2000). But inequality may be harmful for growth because it deprives the poor of the ability to stay healthy and accumulate human capital (Perotti, 1996; Galor and Moav, 2004; Aghion, Caroli, and Garcia-Penalosa, 1999); generates political and economic instability that reduces investment (Alesina and Perotti, 1996); and impedes the social consensus required to adjust to shocks and sustain growth (Rodrik, 1999). Therefore, relationship between inequality and growth may be confusing. For to consider impact of income inequality on economic growth, lag of Gini coefficient has been used.

oCountries that use imported intermediate products and capital equipment's derive benefits because these products embody foreign knowledge. Spillovers arise in this process of knowledge diffusion to the extent the imported products cost less than its opportunity costs including the $\mathrm{R} \& \mathrm{D}$ costs to develop the products. Further, import might facilitate learning about the products (for example, reverse engineering), spurring imitation or innovation of competing products. Thus, countries import new goods first, then produce them by themselves, and eventually export them (Chuang, 1998). Ratio of imported capital and intermediate goods to GDP has been used to indicate effect of imported technologies.

oWe use dummy variable in the model in order to consider the effect of war (19801988 ) on growth. This dummy variable adopts one for war years and zero for other years.

Table 1. List of model's variables.

\begin{tabular}{|c|c|c|}
\hline Variable type & Variable name & $\begin{array}{c}\text { Variable } \\
\text { symbol }\end{array}$ \\
\hline \multicolumn{3}{|l|}{ Dependent variable } \\
\hline & GDP growth rate & GG \\
\hline \multicolumn{3}{|l|}{ Explanatory variable } \\
\hline & Constant term & constant \\
\hline & Ratio of Oil revenue to nominal GDP & $\mathrm{IO}$ \\
\hline & $\begin{array}{l}\text { Ratio of imported capital and intermediate goods to } \\
\text { GDP }\end{array}$ & IK \\
\hline & $\begin{array}{c}\text { The proportion of the working population to total } \\
\text { population }\end{array}$ & $\mathrm{L}$ \\
\hline & The share of exports plus imports to GDP & $\mathrm{XM}$ \\
\hline & Inflation rate & IN \\
\hline & Growth rate of exchange rate & EX \\
\hline & $\begin{array}{c}\text { Logarithm of the ratio of unofficial exchange rate to } \\
\text { official exchange rate }\end{array}$ & $\mathrm{DE}$ \\
\hline & Dummy variable & DW \\
\hline & $\begin{array}{c}\text { Ratio of the number of public high school students to } \\
\text { population }\end{array}$ & EL \\
\hline & $\mathrm{M}_{2}$ to GDP ratio & LM2 \\
\hline
\end{tabular}




$\begin{array}{cc}\begin{array}{c}\text { Lag of ratio of hygiene and treatment expenditure to } \\ \text { GDP }\end{array} & \text { LHG } \\ \begin{array}{c}\text { Lag of ratio of education department expenditure to } \\ \text { GDP }\end{array} & \text { LEG } \\ \text { Lag of ratio of the number of public high school } \\ \begin{array}{c}\text { students to population } \\ \text { Lag of ratio of total private sector loans of banks and } \\ \text { credit institutes to nominal GDP } \\ \text { Ratio of private real investment to GDP } \\ \text { Lag of Gini coefficient }\end{array} \\ \text { LLP } \\ \text { Ratio of government real investment to GDP } & \text { KP } \\ \end{array}$

\subsection{Empirical Results Based on BMA}

One of the most important privileges about BMA analyzing is the high level of trust in coefficients estimated in explanatory variables. Because these coefficients are not estimated based on just one model but they are derived from averaging model of estimated coefficients in every single variable with $131072\left(=2^{17}\right)$ recapitulations or effective samplings. The coefficient for each of BMA estimates is calculated in this way:

$$
\hat{\beta}_{1}=\sum_{i=1}^{I} \lambda_{i} \hat{\beta}_{1 i}
$$

$\lambda_{i}$ Is the possibility of " $\mathrm{i}$ " numbers of model and $\beta_{1 i}$ is an estimation of $\beta_{1}$ which is gained in case of $M_{\mathrm{i}}$ model being. Table (3) shows the t-ratio and the posterior inclusion probability (pip) for each of the BMA estimates which shed some light on the relative importance of each regressor. Now we are going to analyze regarding to the results of table (2):

Table 2. The results of BMA estimation.

\begin{tabular}{|c|c|c|c|}
\hline Variable & Coefficient & t-ratio & pip \\
\hline Constant & -0.6317 & -1.23 & 1.00 \\
\hline Ratio of Oil revenue to nominal GDP & 0.7939 & 2.13 & 0.91 \\
\hline Ratio of imported capital and intermediate goods to GDP & 0.3259 & 2.00 & 0.87 \\
\hline The proportion of the working population to total population & 1.9805 & 1.62 & 0.80 \\
\hline The share of exports plus imports to GDP & -0.0469 & -0.39 & 0.21 \\
\hline Inflation rate & -0.0064 & -0.14 & 0.08 \\
\hline Growth rate of exchange rate & -0.2822 & -0.46 & 0.24 \\
\hline $\begin{array}{l}\text { Logarithm of the ratio of unofficial exchange rate to official } \\
\text { exchange rate }\end{array}$ & 0.0025 & 0.19 & 0.09 \\
\hline Dummy variable & 0.0118 & 0.39 & 0.21 \\
\hline $\begin{array}{c}\text { Ratio of the number of public high school students to } \\
\text { population }\end{array}$ & 1.6016 & 0.51 & 0.38 \\
\hline Lag of $\mathrm{M}_{2}$ to GDP ratio & 0.1242 & 0.57 & 0.33 \\
\hline Lag of ratio of hygiene and treatment expenditure to GDP & -0.1629 & -0.12 & 0.08 \\
\hline Lag of ratio of education department expenditure to GDP & -0.0310 & -0.11 & 0.08 \\
\hline $\begin{array}{c}\text { Lag of ratio of the number of public high school students to } \\
\text { population }\end{array}$ & 0.0470 & 0.02 & 0.23 \\
\hline $\begin{array}{c}\text { Lag of ratio of total private sector loans of banks and credit } \\
\text { institutes to nominal GDP }\end{array}$ & -0.0313 & -0.23 & 0.17 \\
\hline
\end{tabular}




\begin{tabular}{cccc} 
Ratio of private real investment to GDP & 0.0145 & 0.10 & 0.11 \\
Lag of Gini coefficient & -0.4606 & -0.65 & 0.37 \\
Ratio of government real investment to GDP & -0.0767 & -0.33 & 0.15 \\
\hline
\end{tabular}

As a rough guideline for "robustness" of a regressor, a value pip $=0.5$ is sometimes recommended (Raftery, 1995), corresponding approximately with an absolute t-ratio of $|t|=$ 1 (Masanjala and Papageorgiou, 2008). Regarding pip $\geq 0.5$ for robustness of a regressor, the results of the table (2) may be explained as follows:

oWe see that ratio of oil revenue to nominal GDP is by far the most robust auxiliary regressor with pip $=0.91$. It has a positive impact on economic growth. The coefficient of this variable has been obtained 0.79 which indicates that averagely for each percent increase ratio of oil revenue to nominal GDP; \% 0.79 will be added to the economic growth. This result implies that the domestic industry is strictly reliance on oil revenues. This issue for oil exporting countries that with lack of necessary institutional infrastructure to protect themselves against fluctuations in oil revenues, in the empirical growth literature it has been approved. The main transmission channel through which oil income operates is via their effect on private and public capital accumulation. An increase in oil income generates funds not only to consume, but also to invest in public infrastructure. Private investment is often constrained by low domestic savings, and oil incomes are a tool to overcome this restriction. Higher oil incomes cause savings to increase and subsequently investment and capital accumulation, as the revenues are partially spend to modernize the domestic economy. The strength of the impact depends on the absorptive capacity of the economies. Higher imports of capital and intermediate goods may support the adoption of foreign technologies. Private consumption can be affected by government spending as well, for example through an increase of wages in the public sector to mitigate political and social pressure. However, the positive effects cannot be taken as granted. According to the resource curse hypothesis, economies rich in natural resources might experience lower growth than resource-poor economies. Higher oil incomes can also act as an obstacle for long run growth, if they are accompanied by rent seeking.

oThe second effective variable on growth is ratio of imported capital and intermediate goods to GDP with pip $=0.87$. The coefficient of this variable is positive which means an increase in this ratio results increase in economic growth. These imports indeed are technology imports. Higher knowledge accumulation in the richer countries provides them with a comparative advantage in knowledge-intensive/higher productivity products. Countries (such as Iran) that import products from the richer countries where they have a comparative advantage, therefore, derive benefits from the knowledge spillover. The empirical analysis in this paper suggests that Iran's imports of intermediate and capital goods matters for its long-run growth.

oLabor force (the proportion of the working population to total population) is the third important auxiliary regressor with pip $=0.80$ and it has a positive impact on economic growth. It's acceptable according to growth theories (such Solow (1956)), while has less effect then the two variables that cited above. Impact of this variable on long-run Iranian economic growth seems reasonable. because increasing in labor force is means high capacity to produce and yield. Therefore, increase in aggregate demand and subsequently underground economic be coming little and consequently increase in economic growth.

oOther considered variables have not strong correlation with economic growth with pip less than 0.5. In fact it seems the other variables have affected the economic growth from 
main variables of oil revenues, imported intermediate a capital goods and labor force so that after controlling the above variables they have no important effect on economic growth.

\subsection{Selection of Optimum Models}

"STATA" program present VSELECT command in order to select variables after performing a linear regression. This command determine the best subsets of each predictor size by using leaps-and-bounds algorithm and provides the five information criteria ${ }^{1}$ for each of these models in order to select the optimist model. The optimal model is the one model with these qualities: the smallest value of Akaike's information criterion (AIC), Akaike's corrected information criterion (AICc) and Bayesian information criterion (BIC); the largest value of $\mathrm{R}^{2}$ ADJ (adjusted); and a value of Mallows's $C_{p}$ that is close to the number of predictors in the models +1 or the smallest among the other Mallows's $C_{p}$ values. These guidelines help avoid the controversy of which information criterion is the best. Sometimes there is no single model that optimizes all the criteria. There are no fixed guidelines for this situation. Generally, we can narrow the choices down to a few models that are close in optimization (Lindsey and Sheather, 2010). Then we make an arbitrary choice among them. We see the results of vselect command in Table (3):

Table 3. The results of VSELECT command.

\begin{tabular}{lccccc} 
& \multicolumn{5}{c}{ Optimal Models Highlighted: } \\
Preds & R2ADJ & C & AIC & AICC & BIC \\
1: & 151772 & 25.8075 & -98.60946 & 7.11926 & -95.38763 \\
2: & 1736403 & 24.65448 & -98.64842 & 7.603034 & -93.81566 \\
3: & 3234502 & 15.22479 & -105.1539 & 1.783063 & -98.7102 \\
4: & 4671131 & 6.778249 & -113.1242 & -5.322751 & -105.0696 \\
5: & 5068811 & 5.280667 & -115.1686 & -6.305064 & -105.5031 \\
6: & 5671482 & $\mathbf{2 . 7 2 2 4 6 6}$ & -119.2049 & $\mathbf{- 9 . 0 6 0 6 2 9}$ & $\mathbf{- 1 0 7 . 9 2 8 5}$ \\
$7:$ & 5865841 & 2.748556 & -120.1591 & -8.491012 & -107.2718 \\
$8:$ & 6052029 & 2.896974 & -121.1625 & -7.699552 & -106.6643 \\
$9:$ & $\mathbf{6 2 3 8 9 1 3}$ & 3.115425 & $\mathbf{- 1 2 2 . 3 0 2 4}$ & -6.740965 & -106.1932 \\
$10:$ & 618819 & 4.631642 & -121.2032 & -3.201705 & -103.4831 \\
$11:$ & 6073106 & 6.446494 & -119.5538 & 1.273775 & -100.2227 \\
$12:$ & 5952483 & 8.242081 & -117.9447 & 6.147612 & -97.00282 \\
$13:$ & 5800811 & 10.13134 & -116.1583 & 11.70028 & -93.60546 \\
14: & 5629966 & 12.04406 & -114.3275 & 17.87396 & -90.16372 \\
15: & 5428975 & 14.0145 & -112.3852 & 4.82702 & -86.61027 \\
$16:$ & 5204075 & 16.00004 & -110.4131 & 32.58833 & -83.02751 \\
17: & 4951668 & 18 & -108.4132 & 41.29414 & -79.41667
\end{tabular}

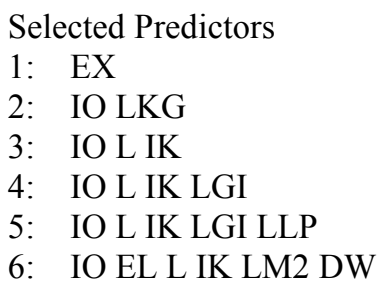

\footnotetext{
${ }^{1}$ An information criterion is a function of a regression model's explanatory power and complexity. The model's explanatory power (goodness of fit) increases the criterion in the desirable direction, while the complexity of the model counterbalances the explanatory power and moves the criterion in the undesirable direction (Sheather, 2009).
} 
7: $\quad$ IO EL L LEL IK LM2 LLP

8: IO EL L LEL IK LM2 XM EX

9: IO EL L LEL IK LM2 XM EX LLP

10: IO EL L LEL IK LM2 XM EX DE DW

11: IO EL L LEL IK LM2 XM EX DE LGI DW

12: IO EL L LEL IK LM2 XM EX DE LGI DW IN

13: IO EL L LEL IK LM2 XM EX DE LGI DW IN KP

14: IO EL L LEL IK LM2 XM EX DE LGI DW IN KP LHG

15: IO EL L LEL IK LM2 XM EX DE LGI DW IN KP LHG LLP

16: IO EL L LEL IK LM2 XM EX DE LGI DW IN KP LHG LLP LKG

17: IO EL L LEL IK LM2 XM EX DE LGI DW IN KP LHG LLP LKG LEG

Invoking vselect on the data, we find that $\mathrm{R}^{2} \mathrm{ADJ}$ and $\mathrm{AIC}$ both select the nine-predictor model. Mallows's $C_{p}$, AICc and BIC advocate the sixteen-predictor model when we choose a model with Mallows's $C_{p}$, AICc and BIC close to the smallest among the other these values. Otherwise, when choosing the smallest $C_{p}$. AICc and BIC values, we will choose the sixpredictor model. It's evident that three variables ratio of Oil revenue to nominal GDP, ratio of imported capital and intermediate goods to GDP, proportion of the working population to total population exists almost in all best (optimal) modals with variety number of regressors. Therefore, results of BMA analysis is confirmed here again.

\section{CONCLUSION}

The economic theories on the growth entail a vast array of potential factors by which economic growth can be influenced. To solve this problem, we employ Bayesian model averaging methods to allow us to partially control for model uncertainty in our analysis. The results indicate that the ratio of oil revenue to GDP is the most robust auxiliary regressor affecting the economic growth. An increase in oil income generates funds not only to consume, but also to invest in public infrastructure. Private investment is often constrained by low domestic savings, and oil incomes are a tool to overcome this restriction. Higher oil incomes cause savings to increase and subsequently investment and capital accumulation, as the revenues are partially spend to modernize the domestic economy. The second influential factor on growth is the ratio of imported intermediate and capital goods to GDP. The coefficient of this variable is positive which means increasing in technology imports is beneficial to Iranian economy growth. One opportunity can be exist for developing countries (such Iran) on import of these goods. In addition of, to receive updated technology brings them economic growth. So the extension of diplomatic relations with other countries, especially those are significant in global trade and establish a direct economic relationship with them, may be suggested. Human capital indicators and physical Investment (including both public and private) have not significant effect on economic growth. Even the coefficient of governmental investments has negative effect on GDP. These results indicate the importance of higher rent-seeking activities and lower productivity hypothesis, especially during boom periods for oil revenues for government investment. In fact, low quality and low productivity of investments and poor allocation reduced the importance of investment's quantity. Trade liberalization variable has left weak impact on economic growth. Semitraditional exports, low productivity and quality of domestic products, lack of appropriate administrative institution for export activities, debility in industrial products (even quantity aspects), difficulties of foreign exchange and investment, and inefficient utilization of 
available resources and reserves are the reasons for these results. Therefore, the nature of Iran's economy has not endogenous and dynamic features and predominantly, economic growth has been made by injecting of exogenous sources (oil revenue, imported capital and intermediate goods, and labor force).

\section{References}

[1] Aghion, P., E. Caroli, and C. Garcia-Penalosa, 1999, "Inequality and Economic Growth: The Perspective of the New Growth Theories," Journal of Economic Literature, Vol. 37(4), pp. 1615-60.

[2] Barro, R. J, \& Lee, J. W. (2000, April and August). International data on educational attainment: updates and implications. CID Working Paper No. 42. Center for International Development at Harvard University, Cambridge, MA.

[3] Brock, W., Durlauf, S.N., 2001. Growth empirics and reality. World Bank Economic Review 15, 229_272.

[4] Chandavarkar, A., 1992. Of finance and development: neglected and unsettled questions. World Development 22, 133-142.

[5] Chuang, Yih-chyi (1998) "Learning by Doing, the Technology Gap and Growth", International Economic Review, 39(3), 697-721.

[6] Danilov, D., \& Magnus, J. R. (2004). On the harm that ignoring pretesting can cause. Journal of Econometrics, 122(1), 27-46

[7] De Luca, G., \& Magnus, J. R. (2011). Bayesian model averaging and weighted average least squares: Equivariance, stability, and numerical issues. Stata Journal, 11(4), 518.

[8] Galor, O., and O. Moav, 2004, "From Physical to Human Capital Accumulation: Inequality and the Process of Development," Review of Economic Studies, Vol. 71(4), pp. 1001-26.

[9] Kaldor, N., 1957, “A Model of Economic Growth,” The Economic Journal, Vol. 67(268), pp. 591-624.

[10]Khan, S.M., Senhadji, A.S., 2000. Financial Development and Economic Growth: An Overview. IMF Working Paper. International Monetary Fund, Washington.

[11] Lazear, E.P., and S. Rosen, 1981, "Rank-Order Tournaments as Optimum Labor Contracts," Journal of Political Economy, Vol. 89(5), pp. 841-64.

[12]Lucas Jr., R.E., 1988. On the mechanics of economic development. Journal of Monetary Economics 22, 3- 42.

[13] Magnus, Jan .R, Powell, Owen \& Prüfer, Patricia (2010). A Comparison Of Two Model Averaging Techniques With An Application To Growth Empirics. Journal of Econometrics 154: 139_153.

[14] Mankiw, N.G., Romer, D., Weil, D.N., 1992. A contribution to the empirics of economic growth. Quarterly Journal of Economics 107, 407_437. 
[15] Masanjala, W, Papageorgiou, C. (2008). Rough And Lonely Road To Prosperity:A Reexamination Of The Sources Of Growth In Africa Using Bayesian Model Averaging. Journal of Applied Econometrics 23, 671_682.

[16] Moral-Benito, Enrique, (2010), Determinants of Economic Growth: A Bayesian Panel Data Approach, CEMFI Working Paper 0719.

[17]Perotti, R., 1996, "Growth, Income Distribution, and Democracy: What the Data Say," Journal of Economic Growth, Vol. 1(2), pp. 149-87.

[18]Phimphan thavong, Hatthachan. (2014) Determinants of Economic Growth in Laos. British Journal of Economics, Management \& Trade 4(1): 35-49.

[19]Raftery, A.E., (1995). Bayesian Model Selection In Social Research. Sociological Methodology 25, 111_163

[20]Robert J. Barro, Ination and Economic Growth, ANNALS OF ECONOMICS AND FINANCE 14-1, 85-109 (2013).

[21] Robinson, J., 1952. The Rate of Interests and Other Essays. Macmillan, London.

[22] Rodrik, D., 1999, "Where Did All the Growth Go? External Shocks, Social Conflict, and Growth Collapses," Journal of Economic Growth, Vol. 4(4), pp. 385-412.

[23] Sheather, S. (2009). A modern Approach to Regression with R, (Vol. 58), New York: Springer.

[24] Wang, Yan \& YAO, Yudong. (2003) Sources of China's economic growth 1952-1999: incorporating human capital accumulation, China Economic Review. No14, pp 32-52.

[25] Christopoulosa, Dimitris K., Tsionas, Efthymios G., Financial development and economic growth: evidence from panel unit root and cointegration tests, Journal of Development Economics 73 (2004) 55- 74. 